\title{
Conception and Evaluation of an Interdisciplinary Lecture on Tooth Extraction versus Tooth Preservation
}

\author{
Bergen Pak ${ }^{1}$, Lukas Seifert ${ }^{2}$, Silvia Brandt ${ }^{3}$, Danielle van Rijt ${ }^{3}$, Beate Schacher ${ }^{4}$, Alexander Uhse ${ }^{5}$, \\ Karina Obreja ${ }^{6}$, Puria Parvini ${ }^{6}$, Susanne Gerhardt-Szep ${ }^{1}$, Sebastian Voss ${ }^{2}$ \\ ${ }^{1}$ Department of Conservative Dentistry, Center for Dentistry and Oral Medicine Carolinum Dentistry University \\ Institute gGmbH Goethe University Frankfurt am Main, Germany \\ ${ }^{2}$ Department of Oral, Cranio and Maxillofacial Plastic Surgery, University Hospital Frankfurt, Goethe University, \\ Theodor-Stern-Kai 7, 60596, Frankfurt am Main, Germany \\ ${ }^{3}$ Department of Prosthodontics, Center for Dentistry and Oral Medicine Carolinum Dentistry University Institute \\ gGmbH of the Goethe University Frankfurt am Main, Germany \\ ${ }^{4}$ Department of Periodontology, Center for Dentistry and Oral Medicine Carolinum Dentistry University Institute \\ gGmbH of the Goethe University Frankfurt am Main, Germany \\ ${ }^{5}$ Department of Orthodontics, Center for Dentistry and Oral Medicine Carolinum Dentistry University Institute \\ gGmbH of the Goethe University Frankfurt am Main, Germany \\ ${ }^{6}$ Department of Oral Surgery and Implantology, Center for Dentistry and Oral Medicine Carolinum Dentistry \\ University Institute gGmbH of the Goethe University Frankfurt am Main, Germany \\ Email: s.voss@voss-dental.de
}

\begin{abstract}
Background: Despite consistent demands, examples of interdisciplinary and evidencebased curricula are rare in dentistry. To address this, the following pilot study describes the conception of an interdisciplinary curriculum on the topic of tooth extraction (TE) vs. tooth preservation (TP). Methods: Based on the German National Learning Objective Catalog on Dentistry, 1408, learning objectives were analyzed, and an interdisciplinary lecture series on TE vs. TP was conceived and conducted. Students' knowledge increase was measured using self-assessment questionnaires on a 6 -step Likert scale (from $1=$ very good to $6=$ insufficient) and by structured evaluation. Results: Overall, the students rated their theoretical knowledge significantly better ( $\mathrm{p}<$ 0.001) and the pilot course was evaluated "well" to "very well" by the students in terms of didactics, relevance, extent, and involvement. Discussion: The pilot course allowed students to choose between tooth extraction and tooth preservation based on an evidence-based and interdisciplinary assessment.
\end{abstract}

Keywords: Dental education, interdisciplinary learning, evidence-based dentistry

\section{Introduction}

One of the biggest challenges in both medical and dental training is to provide students with the skills needed for their future work. In daily practice, a wide range of psychosocial to practical-technical skills must be mastered. This requires in-depth knowledge, which must be mastered at a very high level, since to a certain extent - such as tooth extraction - they are irreversible (Sweet, Wilson, \& Pugsley, 2008). These skills are fostered during intensive competence-based and evidence-based training of aspiring dentists (Chuenjitwongsa, Oliver, \& Bullock, 2018a). Accordingly, during assessments, students must be able to make clinical decisions that are evidence-based and holistic.

Despite numerous efforts throughout Europe to modernize dental training (Cowpe et al., 2010; Hugger, Hugger, \& Kordass, 2011; Shanley, Dowling, Claffey, \& Nattestad, 2002), the content of dental education in Germany is largely based on the outdated licensing regulations for dentists from 1955 (ZApprO). However, this shows a strongly regimented as well as specialized-oriented structure with a focused distinction between the subject structures "Periodontics", "Orthodontics", "Dental Conservation", "Prosthodontics", and "Dental Surgery". There are no references to interdisciplinary, curricular events, or integrated clinical courses. 
In the 2006 draft of a new licensing regulation for dentists, authorized by the Medical Faculty Day, many new approaches were introduced, such as the so-called "integrated clinical dental education", which "promotes interdisciplinary thinking and should be targeted on the teaching subject and crosssectional areas, as relevant" (Bundesverband der Zahnmedizinstudenten in Deutschland e.V, 2014).

A 2005 position paper by the German Science Council also recommends interdisciplinary teaching of dentists, which should enable future graduates to "make synoptic decisions for treatment and care strategies based on medical research" (Wissenschaftsrat, 2005). The demand for the increased integration of interprofessional and scientific evidence-based clinical decision-making into dental curricula can also be found in a 2009 publication by the Association for Dental Education in Europe (ADEE), which states:

"Dental professionals need to act in cooperation with other members of the dental team and other healthcare colleagues in the interests of patients. The teamwork approach should begin during undergraduate dental education and form an integral part of the dental curriculum." (Cowpe et al., 2010)

Inter-professional and evidence-based clinical decision-making also plays a central role in curricular education in the National Competency-based Learning Objective Catalog on Dentistry (NKLZ), which was adopted in 2015 following a long voting phase (Fischer, Bauer, \& Karin Mohn, 2015). Derived from the 2005 published conceptual framework of CanMEDS (Frank \& Danoff, 2007), a dentist should "act professionally through continuous, lifelong learning and through critical evaluation and application of scientific information and its sources" and "work together in teams in a spirit of partnership, respect and effectiveness in order to achieve patient-centered health care" (Medizinischer Fakultätentag der Bundesrepublik Deutschland e.V., n.d.).

Despite these demands, there are few examples of interprofessional teaching in dentistry, and most cases relate to case-based solutions (Evans, Henderson, \& Johnson, 2010; Gräsel \& Mandl, 1993; Kopp, Stark, Heitzmann, \& Fischer, 2009; Oandasan \& Reeves, 2005a, 2005b). From German-speaking countries, Rahman et al. described an interdisciplinary curriculum for clinical education in dentistry in the context of trauma therapy (Rahman et al., 2012). The integration of evidence-based foundations into dental education was published by Forrest in 2006 (Forrest, 2006).

An initial mapping of the university of Frankfurts own curriculum (Gerhardt-Szép et al., 2016) has already identified learning fields that are particularly suitable for an interdisciplinary approach. In particular, the competence to decide between tooth extraction or tooth preservation was promising, as it represents a fundamental aspect of treatment planning in all dental disciplines.

Therefore, the present study aims to provide an exemplary description of a pilot course to promote competence in the decision between tooth preservation or tooth extraction as a fundamental aspect of treatment planning from a multidisciplinary and evidence-based perspective.

From this goal, two research questions emerged: how big was the increase in knowledge after attending the courses; and was there a performance difference between female and male students in terms of knowledge growth?

\section{Methods}

\subsection{Project Preparation and Implementation}

Before the start of the planned course, weekly meetings of an expert group took place. For the group, teachers of the participating polyclinics for dental prosthodontics, periodontics, orthodontics, dental surgery and implantology, dentistry, and the Department of Oral and Maxillofacial Surgery (all specialists and senior physicians, as well as two participants with a Master of Medical Education) were identified as experts. Also, to ensure that the student perspective was taken into account when planning the course, student representatives also participated in the meetings.

However, it was also necessary to optimize the knowledge base for the evidence-based embedding of the planned project. This was done within the group, as one of the authors (Prof. Dr. Gerhardt-Szep) is an educated "evidence-based medicine" teacher, and publications on this topic are also available from the authors (Gerhardt-Szép, Dreher, Rüttermann, \& Weberschock, 2017). Also, the Polyclinic for 
Periodontology has been organizing events on "Clinical Periodontology evidence-based" since 2008, based on current study regulations.

The content of the project was based on the previously created and published study objective of the Dentistry Frankfurt (project Dentes Goethei) (Schacher B, Brandt S,Kandsperger L, Landes C,Locher T,Uhse A,Tent J, Gerhardt-Szep S 2015), as well as the German National Learning Objective Catalog on Dentistry (Medizinischer Fakultätentag der Bundesrepublik Deutschland e.V., n.d.), which was in the final stages of completion when planning this project. In a joint analysis of a total of 1408 learning objectives, work assignments were developed to improve teaching for the participating disciplines of dentistry and medicine, as well as recommendations for the design of interdisciplinary courses. The topic "extraction versus (tooth) preservation" was identified as particularly important for interdisciplinary education, and a total of 13 learning goals were extracted from the NKLZ (see Appendix Table 1).

Below, we present a literature review of evidence-based guidelines, statements, and guidelines at (inter-) national level on the planned topic of the course. This was done by individual preparatory work of the group participants for their respective subject area and subsequent consensus finding within the group.

As a final step in project preparation, a didactic concept for a pilot event was developed within the group. For this, the format of an interdisciplinary lecture was chosen. To increase interactivity, activating technologies (TED voting system and microphone cube) were chosen. The content of the lecture slides (supplements) also took place in individual preparatory work of the group participants for their respective subject area and subsequent consensus finding within the group using Microsoft PowerPoint 2016 (version 16.12, (C) Microsoft Corporation, Redmond, USA).

After completion of all preparations, the pilot event was advertised under all clinical semesters and carried out on 8 December 2015 as part of a 120-min interdisciplinary and interactive facultative lecture. The entire event was video recorded so that the users could access the content again later (e.g., as part of their exam preparations or in the professional context).

\subsection{Measurement of Learning Success}

At the end of the pilot event, the students' knowledge gain was measured using self-assessment questionnaires developed by the group (Appendix Table 3). The students assessed their theoretical knowledge of tooth preservation before and after the course on a 6-point Likert scale (from $1=$ very good to 6 =insufficient). The questionnaire itself contained five questions on the critical assessment and evaluation of the hard tooth substance, the periodontium and the residual dentition, and six questions on the subject-specific approach. After completion of the course, a structured evaluation was carried out. Among other things, the students assessed the didactics of the course, the relevance of the course, its temporal and theoretical content, and student involvement (i.e., its working environment). For this purpose, 6-stage Likert scales (from 1 = very good to $6=$ insufficient) were also used. Also, free-text evaluations were conducted on the strengths of the event and opportunities for improvement.

\subsection{Statistical Evaluation}

Statistical analyses were performed using SPSS (version 19.0, IBM, Armonk, USA). When there was no normal distribution, non-parametric test methods were used. In the case of a normal distribution, corresponding parametric test methods were used. Significant averaging was tested by parametric t-test or the nonparametric Kolmogorov-Smirnov test and Mann-Whitney U-test. The effect intensity Cohen's d was calculated for the mean difference between both groups. As a measure of the correlation, Pearson's correlations and Kendall's Tau-b were calculated.

\subsection{Gender Analysis}

Previous studies in the field of medical education have identified significant differences in learning between the genders (Bienstock, Martin, Tzou, \& Fox, 2002; Carson, Peets, Grant, \& McLaughlin, 2010; Minter, Gruppen, Napolitano, \& Gauger, 2005; Walker, Kay, McLean, \& Haq, 2007). Therefore, to investigate whether participation in the interdisciplinary course led to a differential change in knowledge gain between female and male students, an analysis was carried out between the two genders. The 
average values or medians of the individual items were tested for significant differences as part of the self-assessment before and after attending the course between the genders.

\section{Results}

\subsection{Study Participant}

A total of 100 students (female $=77$, male $=23$ ) in dentistry from the 6 th to the 10th semester participated in both dates of the pilot course. The gender distribution corresponded to the general distribution in the Dentistry study program, (Appendix Table 2)

\subsection{Knowledge Gain}

Overall, the students assessed their theoretical knowledge of tooth preservation after visiting the pilot course as significantly better than before (average value post $=2.49$; average value pre $=3.41 ; \mathrm{p}<$ 0.001) (Appendix Table 3).

We detected no significant difference in self-esteem between the genders before $(\mathrm{p}=0.11)$ and after $(\mathrm{p}=0.39)$ attendance of the course (Appendix Table 3).

\subsection{Evaluation}

In terms of didactics, relevance, extent, and involvement, the pilot course was evaluated "well" to "very well" by the students (Appendix Table 4). In the free-text commentaries, in particular, the interactivity, the interdisciplinary approach to the decision extraction versus receipt, as well as the pleasant and collegial working atmosphere, were positively emphasized. As an opportunity for improvement, an earlier time (standard lecture time 17:15 to 18:30 clock) was proposed.

\section{Discussion}

Evidence-based and interdisciplinary education in dentistry is essential to provide prospective dentists with the necessary clinical decision-making skills to ensure a high quality of oral health care. This need is increasingly urgent in the context of an aging population and the increased incidence of chronic disease (Chuenjitwongsa, Oliver, \& Bullock, 2018b; Rafter et al., 2006; Wilder et al., 2008).

The present study describes the conception of a pilot course to promote the competence of students of dentistry in the decision-making between tooth preservation or extraction as a fundamental aspect of treatment planning under multidisciplinary and evidence-based aspects. Also, the knowledge gained by the students was measured using self-assessment questionnaires specially developed by the group, and the course was evaluated in a structured way.

Overall, the students assessed their knowledge and prognostic ability to critically test the valence of the residual dentition with regard to the decision to extract or preserve a tooth and found that this knowledge was improved by attending the Self-assessment course revealed no significant difference between the genders. Also, regarding the didactics, relevance, temporal and theoretical extent, and involvement, the pilot course was consistently evaluated as "good" to "very good" by the students. At the same time, the teaching staff, in addition to the high competence in their own discipline, were granted an extended insight into the interdisciplinary overview of the patient case.

Previous studies have also examined the learning success of interdisciplinary (Dow \& Thibault, 2017; Güth, Ponn, Mast, Gernet, \& Edelhoff, 2010; Rahman et al., 2012; Wilder et al., 2008) and evidenceand competency-based courses (Cowpe et al., 2010; Levine, Bebermeyer, Chen, Davis, \& Harty, 2008; Sweet et al., 2008) in the context of dental education. For example, Wilder et al. argue that dental faculties have been using interprofessional, interdisciplinary education poorly, although it is becoming increasingly important for aspiring dentists in the context of an increasingly aging and chronically ill population to ensure adequate oral care for oral health care.

In their pilot study, Güth et al. examined the conception and implementation of an interdisciplinary pre-clinical course for learning dental implantology, which was well-evaluated by the 120 participating 
dentistry students. However, only two disciplines were involved in these courses with the Department of Prosthodontics and the Department of Oral and Maxillofacial Surgery, and there was no measurement of students' knowledge growth, leaving the question of teaching effectiveness unanswered (Güth et al., 2010). Levine et al. examined how the development of an interdisciplinary e-learning program on "evidence-based dentistry" affected the learning success of dentistry students $(\mathrm{n}=259)$ and found that students assess themselves significantly better after working on e-learning cases (Levine et al., 2008). Again, these authors did not assess the level of knowledge prior to the intervention. Also, the selected eLearning lesson format did not allow a mutual exchange of teachers from different disciplines nor the student-scholar critical discussion and connection. However, it is precisely this link that enables students to take medically meaningful action based on theoretical foundations. In German-speaking countries, Rahman et al. teach an interdisciplinary curriculum for the treatment of dental trauma. After completing a four-part series of lectures, a performance assessment was carried out using MC tests, in which no significant differences could be found between the participating semesters (6th to 10th semester) (Rahman et al., 2012). However, in this study, knowledge prior to the intervention was not tested. As a result, to what extent the intervention itself has contributed to the learning success remains unclear. Unlike these studies, the present study shows that teaching in the context of an interdisciplinary designed and conducted, as well as interactive, lecture series on the subject of tooth extraction versus tooth preservation leads to a significant increase in knowledge among students of dentistry.

The present study has some limitations. First, the participants had an unequal gender distribution. Previous studies have shown that female and male medical students differ significantly in academic achievement (Bienstock et al., 2002; Carson et al., 2010; Haq, Higham, Morris, \& Dacre, 2005) and selfassessment (Minter et al., 2005). However, by self-analysis, these authors detected no significant difference, which is consistent with our findings reported here. Furthermore, the objective of the present study was not to use objective tests to measure knowledge growth, although previous studies have shown that self-assessed competence often deviates from actual competence (Davis et al., 2006). Further research is also needed to examine how the present results can be transferred to other dental competences or departments with other curricular structures.

\section{Conclusion}

The pilot course described in this study allowed students to choose between tooth extraction and tooth preservation based on an evidence-based and interdisciplinary assessment. Also, the learning content of the participating clinics was equalized in terms of time and content. The pilot course made it possible to combine the previously largely unrelated knowledge from the participating disciplines, to discuss the case of the patient and, thus, to illustrate the realities of future professional life during the studies. At the same time, the teaching staff, in addition to the high competence in their own discipline, were granted an extended insight into the interdisciplinary overview of the patient case. In addition to the content already described, the cooperation and consensus-finding within the individual polyclinics were optimized. This will benefit both the learners and the teachers in the long term.

\section{References}

1. Schacher, B., Brandt, S., Kandsperger, L., Landes,C., Locher, T., Uhse, A. \& Tent, J., Gerhardt-Szep, S. (2015). Dentes Goethei - an interdisciplinary project to evaluate the Frankfurt curriculum in dentistry. European Journal of Dental Education, 19(1), e18.

2. Bienstock, J. L., Martin, S., Tzou, W. \& Fox, H. E. (2002). Medical Students' Gender is a Predictor of Success in the Obstetrics and Gynecology Basic Clerkship. Teaching and Learning in Medicine, 14(4), 240-243. https://doi.org/10.1207/S15328015TLM1404_7

3. Bundesverband der Zahnmedizinstudenten in Deutschland e.V. (2014). Informationen zur neuen Approbationsordnung für Zahnmediziner (AOZ Version 8). Retrieved from https://www.zahniportal.de/ fileadmin/mediensammlung/dentalfresh/2005_02/df0205_06_07_approbation.pdf

4. Carson, J. A., Peets, A., Grant, V. \& McLaughlin, K. (2010). The Effect of Gender Interactions on Students' Physical Examination Ratings in Objective Structured Clinical Examination Stations. Academic Medicine, 
85(11), 1772-1776. https://doi.org/10.1097/ACM.0b013e3181f52ef8

5. Chuenjitwongsa, S., Oliver, R. G. \& Bullock, A. D. (2018a). Competence, competency-based education, and undergraduate dental education: a discussion paper. European Journal of Dental Education, 22(1), 1-8. https://doi.org/10.1111/eje.12213

6. Cowpe, J., Plasschaert, A., Harzer, W., Vinkka-Puhakka, H. \& Walmsley, A. D. (2010). Profile and Competences for the European Dentist- update 2009. Eur J Dent Educ, 14(4), 193-202.

7. Davis, D. A., Mazmanian, P. E., Fordis, M., Van Harrison, R., Thorpe, K. E. \& Perrier, L. (2006). Accuracy of Physician Self-assessment Compared With Observed Measures of Competence. JAMA, 296(9), 1094. https://doi.org/10.1001/jama.296.9.1094

8. Dow, A. \& Thibault, G. (2017). Interprofessional Education - A Foundation for a New Approach to Health Care. New England Journal of Medicine, 377(9), 803-805. https://doi.org/10.1056/NEJMp1705665

9. Evans, J., Henderson, A. \& Johnson, N. (2010). The future of education and training in dental technology: designing a dental curriculum that facilitates teamwork across the oral health professions. British Dental Journal, 208(5), 227-230. https://doi.org/10.1038/sj.bdj.2010.208

10. Fischer, M. R., Bauer, D. \& Karin Mohn, N. (2015). Finally finished! national competence based catalogues of learning objectives for undergraduate medical education (NKLM) and dental education (NKLZ) ready for trial. GMS Zeitschrift Fue3r Medizinische Ausbildung, 32(3).

11. 12. Forrest, J. L. (2006). Treatment Plan for Integrating Evidence-Based Decision Making into Dental Education. Journal of Evidence Based Dental Practice, 6(1), 72-78. https://doi.org/10.1016/ J.JEBDP.2005.12.022

12. Frank, J. R., \& Danoff, D. (2007). The CanMEDS initiative: implementing an outcomes-based framework of physician competencies. Medical Teacher, 29(7), 642-647. https://doi.org/10.1080/01421590701746983

13. Gerhardt-Szép, S., Brandt, S., Hoefer, S. H., Kandsperger, L., Landes, C., Locher, T. \&Uhse, A. (2016). Interdisziplinäre Curriculumskartierung der Frankfurter zahnmedizinischen Ausbildung anlehnend an den NKLZ. Dtsch Zahnärztl , (71). https://doi.org/10.3238/dzz.2016.0129-0135

14. Gerhardt-Szép, S., Dreher, S., Rüttermann, S. \& Weberschock, T. (2017). Konzeption und Implementierung eines neuartigen E-Learning-Moduls mit EbM-Lerninhalten im Fach Zahnerhaltungskunde. Zeitschrift Für Evidenz, Fortbildung Und Qualität Im Gesundheitswesen, 127-128, 72-78. https://doi.org/10.1016/ j.zefq.2017.09.001

15. Gräsel, C. \& Mandl, H. (1993). Förderung des Erwerbs diagnostischer Strategien in fallbasierten Lernumgebungen. Unterrichtswissenschaft 21, (4), 355-369.

16. Güth, J. F., Ponn, A., Mast, G., Gernet, W. \& Edelhoff, D. (2010). Description and evaluation of a new approach on pre-clinical implant dentistry education based on an innovative simulation model. European Journal of Dental Education, 14(4), 221-226. https://doi.org/10.1111/j.1600-0579.2009.00614.x

17. Haq, I., Higham, J., Morris, R., \& Dacre, J. (2005). Effect of ethnicity and gender on performance in undergraduate medical examinations. Medical Education, 39(11), 1126-1128.

18. Hugger, A., Hugger, S. \& Kordass, B. (2011). Dental education in Germany: new concepts for the dental curriculum. Bundesgesundheitsblatt, Gesundheitsforschung, Gesundheitsschutz, 54(9), 1046-1051. https://doi.org/10.1007/s00103-011-1328-8

19. Kopp, V., Stark, R., Heitzmann, N. \& Fischer, M. R. (2009). Self-regulated learning with case-based worked examples: effects of errors. Evaluation \& Research in Education, 22(2-4), 107-119. https://doi.org/10.1080/ 09500790903494518

20. Levine, A. E., Bebermeyer, R. D., Chen, J.-W., Davis, D. \& Harty, C. (2008). Journal of Dental Education, 72(9), 1067-1076.

21. Medizinischer Fakultätentag der Bundesrepublik Deutschland e.V. (n.d.). Nationaler Lernzielkatalog Zahnmedizin - Kapitel 2 Kompetenzen, Rollen und Lernziele - NKLZ. Retrieved December 19, 2018, from http://www.nklz.de/kataloge/nklz/lernziel/uebersicht

22. Minter, R. M., Gruppen, L. D., Napolitano, K. S. \& Gauger, P. G. (2005). Gender differences in the selfassessment of surgical residents. American Journal of Surgery, 189(6), 647-650. https://doi.org/10.1016/ j.amjsurg.2004.11.035

23. Oandasan, I., \& Reeves, Sc. (2005b). Key elements for interprofessional education. Part 1: The learner, the educator and the learning context. Journal of Interprofessional Care, 19(sup1), 21-38. https://doi.org/ $10.1080 / 13561820500083550$

24. Oandasan, I. \& Reeves, S. (2005a). Key elements of interprofessional education. Part 2: Factors, processes and outcomes. Journal of Interprofessional Care, 19(sup1), 39-48. https://doi.org/10.1080/13561820500081703 
25. Rafter, M. E., Pesun, I. J., Herren, M., Linfante, J. C., Mina, M., Wu, C. D. \& Casada, J. P. (2006). A Preliminary Survey of Interprofessional Education. Journal of Dental Education, 70(4), 417-427.

26. Rahman, A., Meyer, K., Jacker-Guhr, S., Eberhard, J., Delling, A., Heuer, W. \& Geurtsen, W. (2012). Interdisziplinäres Curriculum für die klinische Ausbildung in der Zahnmedizin. Retrieved from https://www.egms.de/static/en/meetings/gma2012/12gma128.shtml

27. Shanley, D. B., Dowling, P. A., Claffey, N. \& Nattestad, A. (2002). European convergence towards higher standards in dental education: the DentEd Thematic Network Project. Medical Education, 36(2), 186-192. https://doi.org/10.1046/j.1365-2923.2002.01125.x

28. Sweet, J., Wilson, J. \& Pugsley, L. (2008). Chairside teaching and the perceptions of dental teachers in the UK. British Dental Journal, 205(10), 565-569. https://doi.org/10.1038/sj.bdj.2008.983

29. Walker, D., Kay, L., McLean, M. J. \& Haq, I. (2007). Validation of MSAT: an instrument to measure medical students' self-assessed confidence in musculoskeletal examination skills. Medical education, 41(4), 402-410.

30. Wilder, R. S., O'donnell, J. A., Barry, J. M., Dominique, M. B. A., Galli, M., Foroud, F.\& Robbins, M. R. (2008). Is Dentistry at Risk? A Case for Interprofessional Education. Journal of Dental Education, 72(11), 12311237.

31. Wissenschaftsrat. (2005). Empfehlungen zur Weiterentwicklung der Zahnmedizin an den Universitäten in Deutschland. Retrieved from https://www.wissenschaftsrat.de/download/archiv/6436-05.pdf

\section{Appendix}

Table 1. Extracted learning objectives on the subject of tooth extraction vs. tooth preservation from the German National Learning Objective Catalog Dentistry

Learning Objectives

1 You can perform a specific and patient-related medical history and diagnostics. You can perform a targeted history after tooth loss or missing teeth that includes previous therapies or treatments (examples: reasons for tooth loss, oral and prosthetic hygiene, satisfaction with existing care).

2 You can collect relevant patient-specific influencing factors and, if necessary, record further factors individually (example: age including life expectancy, psychosocial context, and risks, compliance, oral hygiene and behavior, dietary habits and habits, fears and fears, socio-economic background, oral healthrelated quality of life).

3 You can assess and evaluate the extent to which the patient's subjective data on his finding for tooth loss or his treatment can be objectified (example: discrepancy between subjective feeling on the one hand and the objective dental and general findings/condition on the other).

4 You can identify the need for further relevant information in the sense of interdisciplinary or interdisciplinary cooperation and/or relatives to be collected and considered (for example: before and with treating dentists and physicians and, if applicable, caregivers and non-medical therapists, caregivers, family caregivers, aesthetic assessment of life partners.)

5 You can critically evaluate the value of teeth to be treated and the quality of the remaining payment (example: related to hard tooth substance, endodontic, periodontium, bite-functional parameters, the status of dentition development, and localization).

6 They carry out a treatment plan for tooth hard tissue defects. You can make the indication for the maintenance or extraction of a tooth due to hard tooth substance defects (examples: extraction due to carious destruction).

$7 \quad$ You can explain the causes of tooth loss, explain its importance to the patient, conduct a comprehensive assessment and diagnostics, and create an indication-based treatment plan. They explain epidemiological factors and the causes of tooth loss, as well as related pathophysiological changes in oral structures, and their impact on purchasing function, aesthetics, communication, and quality of life. You can name the causes of tooth loss related to therapy and describe specific effects on planning and prognosis (e.g., as a result of orthodontic or prosthetic treatment, functional or orthodontic treatment (radiotherapy, tumor resection).

8 You may describe the disease-related causes of tooth loss as a result of tooth hard tissue, endodontic, and/or periodontal disease. 
9 You can explain reversible and irreversible local effects that may arise due to missing teeth/tooth loss (example: tilting and / or elongation, tooth migration, occlusion disorders, attrition, alveolar ridge atrophy, etc.)

10 They can explain reversible and irreversible effects and limitations of a general nature that might arise due to missing teeth/tooth loss (examples: limitations on mastication, temporomandibular joint function, phonetics and (facial) aesthetics, thus, again (mouth health-related) quality of life).

11 You can see findings with tooth loss where no damage is expected.

12 You can make, perform, or induce the indication for removal of deciduous teeth and permanent teeth, as well as control complications. You can make the indication for tooth removal based on the severity of diseases of the periodontium, the endodontics, the hard tooth tissue or the position of the tooth (example: extraction, for example, also from an orthodontic indication).

13 You may consider the indication for tooth removal or deciduous tooth removal as a necessary effect of other dental procedures (examples of orthodontic or prosthetic treatments, rehabilitation prior to radio therapy.

Table 2. Gender- and semester distribution of study participants

\begin{tabular}{cccccc}
\hline Gender & Female & male & & & \\
\cline { 1 - 3 } & 77 & 23 & & & \\
\hline semester & 6 th & 7 th & 8 th & 9 th & 10 th \\
\hline $\mathrm{n}$ & 26 & 26 & 31 & 9 & 8 \\
\hline
\end{tabular}

Table 3. Results of self-assessment of students before ( $\mathrm{w}$ and $\mathrm{m}$ pre) and after ( $\mathrm{w}$ and $\mathrm{m}$ post) participation in the pilot class.

\begin{tabular}{|c|c|c|c|c|c|c|c|c|}
\hline Item & $\mathrm{n}$ & $\begin{array}{l}\text { Male } \\
\text { pre }\end{array}$ & $\begin{array}{c}\text { female } \\
\text { pre }\end{array}$ & $\begin{array}{l}\text { p-value } \\
\text { pre }\end{array}$ & $\begin{array}{c}\text { Male } \\
\text { post }\end{array}$ & $\begin{array}{c}\text { female } \\
\text { post }\end{array}$ & $\begin{array}{l}\text { p-value } \\
\text { post }\end{array}$ & $\begin{array}{l}\mathrm{p}-\text { Wert } \\
\text { pre -post }\end{array}$ \\
\hline $\begin{array}{l}\text { I can critically evaluate the value of the } \\
\text { supplying teeth }\end{array}$ & 98 & 3.1 & 3.2 & 0.49 & 2.4 & 2.4 & 0.89 & $<0.001$ \\
\hline $\begin{array}{l}\text { I can critically test the quality of the } \\
\text { residual dentition. }\end{array}$ & 99 & 3.0 & 3.2 & 0.50 & 2.4 & 2.5 & 0.94 & $<0.001$ \\
\hline $\begin{array}{l}\text { I can relate my critical examination to the } \\
\text { hard tooth substance. }\end{array}$ & 98 & 2.6 & 3.0 & 0.14 & 2.2 & 2.3 & 0.70 & 0.001 \\
\hline $\begin{array}{l}\text { I can relate my critical examination to the } \\
\text { endodontics. }\end{array}$ & 98 & 3.2 & 3.4 & 0.43 & 2.4 & 2.6 & 0.38 & $<0.001$ \\
\hline $\begin{array}{l}\text { I can relate my critical exam to the } \\
\text { periodontium. }\end{array}$ & 97 & 3.5 & 3.8 & 0.43 & 2.4 & 2.7 & 0.35 & $<0.001$ \\
\hline $\begin{array}{l}\text { I can take into account specific aspects of } \\
\text { the oral- and maxillofacial approach. }\end{array}$ & 98 & 3.7 & 4.4 & 0.12 & 2.6 & 2.4 & 0.83 & $<0.001$ \\
\hline $\begin{array}{l}\text { I can take into account specific aspects of } \\
\text { the orthodontic approach. }\end{array}$ & 98 & 3.6 & 3.6 & 0.95 & 2.2 & 2.3 & 0.21 & $<0.001$ \\
\hline $\begin{array}{l}\text { I can consider special aspects of the } \\
\text { conservative approach. }\end{array}$ & 97 & 2.4 & 2.7 & 0.16 & 1.9 & 2.7 & 0.20 & 0.029 \\
\hline $\begin{array}{l}\text { I can consider specific aspects of the oral } \\
\text { surgical approach. }\end{array}$ & 95 & 3.6 & 4.3 & 0.08 & 2.5 & 2.7 & 0.60 & $<0.001$ \\
\hline $\begin{array}{l}\text { I can consider special aspects of the } \\
\text { periodontic approach. }\end{array}$ & 94 & 3.7 & 3.9 & 0.65 & 2.6 & 2.7 & 0.53 & $<0.001$ \\
\hline $\begin{array}{l}\text { I can consider specific aspects of the } \\
\text { prosthetic approach. }\end{array}$ & 93 & 2.9 & 3.4 & 0.99 & 2.5 & 2.6 & 0.41 & 0.002 \\
\hline Mean & 98.4 & 3.2 & 3.5 & 0.11 & 2.4 & 2.5 & 0.39 & $<0.001$ \\
\hline
\end{tabular}


Table 4. Evaluation of the pilot course in terms of didactics, relevance, extent and involvement $(\mathrm{N}=$ evaluation participants, $\mathrm{MW}=$ mean value, $\mathrm{SD}=$ standard deviation).

\begin{tabular}{|c|c|c|c|}
\hline & $\mathrm{N}$ & $\mathrm{M}$ & SD \\
\hline \multicolumn{4}{|l|}{ Didactics } \\
\hline The event was well organized & 37 & 1.6 & 0.9 \\
\hline The lecture gave a good overview of the topic. & 37 & 1.8 & 1 \\
\hline The substance was illustrated by examples. & 37 & 1.6 & 0.7 \\
\hline \multicolumn{4}{|l|}{ Relevance } \\
\hline $\begin{array}{l}\text { The event made me well acquainted with the issue of "tooth } \\
\text { preservation or tooth extraction". }\end{array}$ & 38 & 2.1 & 0.8 \\
\hline $\begin{array}{l}\text { The relationship between the mediated substance and the later practice } \\
\text { is sufficient. }\end{array}$ & 37 & 2.4 & 1 \\
\hline The mediated content I think is very useful. & 35 & 1.9 & 1 \\
\hline \multicolumn{4}{|l|}{ Scope and adequacy of the event } \\
\hline You could easily follow the learning content of the event. & 35 & 2.0 & 0.9 \\
\hline Some issues were not sufficiently explained. & 37 & 3.3 & 1.4 \\
\hline There was too much content in the event. & 32 & 3.3 & 1.5 \\
\hline \multicolumn{4}{|l|}{ Involvement } \\
\hline I enjoyed participating in the event. & 34 & 1.8 & 0.9 \\
\hline The working atmosphere in the lecture was pleasant. & 32 & 1.5 & 0.7 \\
\hline The treated learning content corresponded to my interests. & 35 & 1.8 & 1.1 \\
\hline
\end{tabular}

